Review Article

\title{
Sterilization and Upkeep of Laparoscopic Instruments and Equipment
}

\author{
Shams ul Bari, M.S., 'Ajaz A Malik, M.S. ${ }^{2}$ \\ 'Associate Professor surgery, Skims Medical College, Srinagar, Kashmir \\ ${ }^{2}$ Professor of Surgery Skims, Soura Srinagar, Kashmir
}

Sterilization is the absolute elimination or destruction of all forms of microbial life including spores. The aim of effective sterilization is to provide sterile product to the surgeon and to the patient ${ }^{1}$. On the other hand disinfection is the relative removal of pathogenic organisms except spores. Disinfection can be of three types.

a) High level - where all life forms of microbial life except the spores are destroyed,

b) Intermediate level-where some fungi, viruses and spores are spared,

c) Low-level - where fungi, viruses, spores and mycobacteria remain undestroyed.

\section{Laparoscopic vs open instruments:}

Laparoscopic surgery requires sophisticated and precisely calibrated instruments. Laparoscopic instruments are more complex in design and delicate in construction. They are more vulnerable to lodging of bio burden (microorganisms and debris) within their crevices. That is why it is difficult to clean and sterilize and maintain laparoscopic instruments as compared to instruments used in open surgery .Therefore ,meticulous cleaning and maintenance of Laparoscopic instruments in addition to sterilization is necessary so that there is no compromise on the safety of the patient, safety of the surgeon or safety of other operating room personnel.

\section{Steps of sterilization:}

Optimal care of laparoscopic instruments involves several steps to reduce the risk of transmitting infection from used

\section{Correspondence}

Dr. Shams ul Bari, M.S.

Associate Professor surgery,

SKIMS Medical College, Srinagar, Kashmir

Email; shamsulbari@rediffmail.com instruments and it is essential to perform the steps in correct $\operatorname{order}^{1-4}$. They are: 1) Dismantling, 2) Decontamination, 3) Precleaning, 4) Cleaning and rinsing, 5) Drying 6) Sterilization and 7) Storage

\section{Dismantling:}

Current recommendations specify dismantling of most of laparoscopic instruments before sterilisation.

- Instruments that can't be dismantled completely are prone to harbour blood / debris within the shafts and compromise safety of the patients in whom they are utilised subsequently.

- In those instruments which cannot be dismantled ,there is a separate channel to irrigate water under pressure to clean it.At least $300 \mathrm{ml}$ of water should be flushed through these instruments to clean it.

\section{Decontamination:}

- Decontamination is the procedure used to reduce bio burden on reusable medical devices.

- $\quad$ The procedure begins in the theatre itself .Nursing staff wipes off visible blood tissue and body fluids in the instruments with a damp sterile sponge.

- This is followed by placing all soiled or contaminated instruments in a container containing a disinfectant solution such as $0.5 \%$ chlorine for Ten minutes

- The instruments shouldn't be left in this solution for longer period of time as they could get damaged

- Instruments with an external gasket or no gasket are placed in the vertical position in enzymatic cleaning and rinsing solutions, instead of the standard horizontal position, 
- The aim is that the air trapped within the instrument is permitted to escape and replaced by the solution.

- During the process of decontamination, special attention should be given to intricate and delicate operating mechanisms located at the distal end of many instruments..

\section{Precleaning:}

- $\quad$ Pre-cleaning treatment with an enzymatic method is preferably carried out in CSSD

- Numerous enzymatic products are available, viz. protease, lipase, amylase, which are effective in enhancing the cleansing process for difficult-to-clean instruments.

- These enzymatic solutions break up any blood and or proteinacious tissue attached to instruments. .

\section{Cleaning:}

- Laparoscopic Instruments require specific techniques for cleaning just before sterilization and the aim is that there should be no residual, proteinaceous material or organic residue on the surface of instruments or its crevices. This is particularly important for instruments with several small moving parts. otherwise build-up of residues may eventually result in corrosive damage and pathogenic colonization (bio burden). Many hospitals adopt the technique of washing their instruments in soap scrubs. Others use enzymatic and detergent based cleaners which dissolve and lift organic material from the surface of instruments

- For laparoscopic instruments this is best achieved by using soft brushes that allow the inner surfaces from the instruments to be cleaned thoroughly

Ultra-sonic Cleaning: As a method of cleaning this method is gaining popularity. The instruments are placed in the ultrasonic unit containing neutral $\mathrm{PH}$ solution for 10-15 minutes This method is, by far, the most efficient and most effective, simple and preferred choice. Ultrasonic cleaning is 16 times better than hand-cleaning.

\section{Precautions during ultra-sonic cleaning:}

The instruments should be free from all visible debris. Do not mix instruments made of dissimilar metals in the same cycle such as Aluminium and stainless steel. The ultrasonic cleaner shouldn't be overloaded. All instruments should be opened so that ratchets and box locks are fully subjected to the cleaning process.

\section{Rinsing:}

- Next step is rinsing laparoscopic instruments in running water to completely remove all the particulate matter and any residues of chemicals used for contamination and cleaning process.

- “Cleaning guns" with fine, pointed nozzles to wash the shafts are quite effective.

- The jet of water from these cleaning guns have the capacity to clean these instruments much better than rinsing them in stagnant water

\section{Drying:}

- The instruments should be dried at the end of the cleaning and rinsing cycle before they are packed for sterilization.

- Drying is ideally achieved by using an air gun that blows all the water droplets off the surfaces of instruments or by using an oven (available only in CSSD units)

\section{Sterilization:}

- The Centres for Disease Control (CDC) recommends that rigid laparoscopic instruments should be sterile or, in the event that isn't feasible, they be high-level disinfected.

- $\quad$ There are two main methods of sterilization processes available; steam sterilization and chemical sterilization(ethylene oxide and peracetic acid).

- Because of product knowledge and proprietary design information, the instrument manufacturer may be the just one who can provide sterilization recommendations.

Steam sterilization in an autoclave is among the most typical forms of sterilization

Used in healthcare facilities. It is the oldest, effective, cheap and non-toxic method $d^{5,6}$. Autoclaving at $121^{\circ} \mathrm{C}$ for 15 minutes is ideal for all reusable metal

Instruments. Flash Sterilization of laparoscopes is carried out at $135^{\circ} \mathrm{C}$ for $10-15$ minutes. 


\section{Limitations of Sterilizations:}

- Before sterilization, all instruments that are insulated, all silicone tubing, and all sorts of cords must be doubly covered with a cloth to prevent connection with the hot metallic container.

- Although, most of the laparoscopic instruments can be safely autoclaved, it takes too long and some laproscopic instruments cannot withstand the prolonged heat and moisture and get damaged such as Laproscopic cameras, laproscopes, light cables and flexible endoscopes

- Alternative methods are needed to sterilize these moisture sensitive and heat sensitive laparoscopic instruments and chemical sterilization is recommended for many such instruments

- Laproscopic camera is damaged by chemical sterilization and sterile plastic covers or sterile camera covers can be used.

\section{Chemical sterilization:}

- Ethylene oxide (EO) is one of the commonest types of chemical sterilization used since 1950 . It is used for all disposable instruments, insulated hand instruments and Tubing's employed for gas, suction and irrigation. Endoscopic instruments may be sterilized with either cold or warm EO gas, with respect to the manufacturer's instructions ${ }^{1,7-9}$.

- With cold gas, the temperatures are set at $85^{\circ} \mathrm{C}$ and the instruments are subjected for 4 hours and 30 minutes followed by Aeration for 12 hours.

- Warm gas sterilization happens at $145^{\circ} \mathbf{C}$ for 2 hour 30 minutes, followed by 8 hours aeration.

Benefits of EO are that Items aren't damaged, it's noncorrosive to optics and Permeates porous material.

Disadvantages of EO are that it is costly, extremely toxic and inflammable, .The aeration is required and process takes long process (total almost 20 hours). Therefore should be used only when time is not a factor.

\section{High level disinfection:}

- When sterilization isn't available or feasible, highlevel disinfection (HLD) is used .

- HLD eliminates bacteria, viruses, fungi, and parasites but doesn't reliably kill all bacterial endospores, which cause diseases such as tetanus, gas gangrene and atypical mycobacterial infections.

- The effectiveness of HLD depends on the amount and kind of microorganisms, type of organic material (blood, other fluids or any tissues) $)^{9,10}$.

- Therefore it is important to decontaminate and thoroughly clean instruments along with other items before HLD.

- Agents that are employed for HLD include $2 \%$ glutaraldehyde, $6 \%$ stabilized hydrogen peroxide and $0.2 \%$ Per acetic acid.

\section{Gultaraldehyde(Cidex):}

An activated 2\% glutaraldehyde solution is considered as an effective liquid chemical sterilant ${ }^{5,6}$. The efficiency of glutaraldehyde is influenced by the organic load, contact time, physical configuration of instruments temperature, concentration and $\mathrm{PH}$. Established maximum allowable exposure limit for glutaraldehyde is $0.2 \mathrm{ppm}^{1,6,7}$

\section{Benefits of Glutaraldehyde:}

- It has good biocidal activity, is non-corrosive to optics and is active in the presence of protein.

\section{Disadvantages:}

- Glutaraldehyde is irritating towards the skin, eyes, and respiratory system, especially at concentrations of 0.3 parts per million (ppm) ${ }^{6}$.

\section{Immersion time in cidex:}

- Telescopes and Fibre optic light cords -Ten minutes. Soaking should not exceed Twenty minutes.

- The endocamera gets disinfected by 10 minutes submersion

- $\quad$ Care must be come to leave the plug end of the cords away from solution.

- Other metallic instruments, including trocars, and hand instruments, should be kept for $60 \mathrm{~min}$. to avoid infection with a typical mycobacterial infection.

\section{Precautions:}

- Commercially available glutaraldehyde solutions may be used from 14-30 days.

- It should be used maximum 15 times and replaced if it becomes cloudy

- It ought to be tested daily with the manufacturer's test 
strip.

- Always stick to the manufacturer's instructions regarding proper storage temperatures and expiration date.

\section{Orthophth-alaldehyde (0.55\%)-Cidex OPA:}

- It is non-glutar aldehyde solution for disinfecting delicate instruments.

- It is fast acting, effective and safe.

- No activation is required.

- It can substantially reduce instrument damage and repair cost

- Can be used for both automated and manual processing and has shelf life of two years and open bottle shelf life of 75 days

- Rapid 5 min immersion time at a temperature of $26^{\circ} \mathrm{C}$ in an automatic endoscope processor

- 12 min, immersion time at room temperature $\left(20^{\circ} \mathrm{C}\right)$ for manual processing

- Effective against glutaraldehyde resistant mycobacterium $^{10-12}$.

\section{Formalin tablets}

- $\quad 37 \%$ aqueous solution (formalin) or $8 \%$ formaldehyde in $70 \%$ isopropyl alcohol kills micro-organisms by coagulation of intracellular proteins at room temperature.

- Specially designed airtight chambers are used.

- $\quad 8$-10 formalin tablets are placed in chamber and door is closed.

- Vapour of formalin act for one week, after one week tablets should be changed

- Although it also destroys spores ,but takes 12 to 24 hours to be effective.

- Disadvantages of formaldehyde are Pungent odor of formalin which is quite irritating to the eyes and nasal passages and respiratory tract. Vapours are toxic and may have carcinogenic effects.

For this reason, routine utilization of formaldehyde for sterilizing instruments and other items isn't recommended.

Newer methods of sterilization (STERRAD):
- Hydrogen peroxide bactericidal, virucidal, sporicidal and fungicidal even at low concentration and temperature.

- Hydrogen peroxide vapour and low-temperature gas plasma is an effective sterilizing agent ${ }^{12,13}$

- Most of the devices are sterilized quickly with no toxic residues.

- A solution of hydrogen peroxide and water $(59 \%$ peroxide by weight) is vaporized into the closed chamber.

- The product to be sterilized will be enveloped within the peroxide vapour.

The pressure in the chamber is reduced, permitting the generation of low-temperature gas plasma. Strong electric field is then applied . The plasma breaks down the peroxide into the cloud of highly energized species composed of ions ,electrons and atomic particles.

\section{Advantages:}

No aeration time is required, instruments can be sterilized in less than one hour and can be be used immediately. This method is important for hospitals with high workload and is good alternative for instruments that can't be sterilized satisfactorily with steam or dry heat ${ }^{13-15}$.

\section{Per-acetic acid:}

- Per-acetic acid (0.2 to $0.35 \%)$ is acetic acid plus an extra oxygen atom and reacts with most cellular components to cause cell death. This solution is heated to 50 to $56^{\circ} \mathrm{C}$ during $20-30 \mathrm{~min}$. cycles.

- Anti-corrosive additives should be added to solution.

- After sterilization instruments must be rinsed with copious amount of sterile water.

Advantages: Relatively short procedure, no aeration time is required and instruments can be used immediately ${ }^{7 .}$ 10

\section{Storage of instruments:}

- Proper storage is as important as sterilization, or HLD.

- For optimal storage, sterile packs are put in closed cabinets in areas that aren't heavily trafficked, have moderate temperatures, and are dry or have low humidity.

- Under optimal storage conditions and with minimal 
handling, properly wrapped items can be considered sterile as long as they remain intact and dry

- Storage and handling of sterile packs must be minimum, because the probability of contamination increases over time and with increased handling.

\section{CONCLUSION}

- Most of the laparoscopic instruments can be easily sterilized if the person knows how to dissemble, clean and use specific chemical for sterilization .

- Manufacturer's instruction is important to follow if desired effect has to be achieved.

- Instruments should be handled carefully and all the insulated instruments should be checked thoroughly for any breach in insulation before sterilization.

\section{REFERENCES}

1. Rutala W: APIC guideline for selection and use of disinfectants. Am I Infect Control. 1900; 18:99117.

2. Spaulding EH: Chemical disinfection of medical and surgical materials. In: Lawrence CA, Block SS, eds. Disinfection, Sterilization, and Preservation. Philadelphia, Lea \& Febiger, 1968. p. 517531.

3. Vesley D, Norlien KG, Nelson B, et al. Significant factors in the disinfection and sterilization of flexible endoscopes. Am I Infect Control. 1992; 20:291300.

4. Rutala WA, Clontz EP, Weber DJ, et al. Disinfection practices for endoscopes and other semicritical items. Infect Control Hosp Epidemiol. 1991; May:282296.

5. Newman MA, Kachuba JB. Glutaraldehyde: A potential health risk to nurses. Gastroent Nursing. 1992; June:296301.

6. Centers for Disease Control: Symptoms of irritation associated with exposure to glutaraldehydeColorado. MMWR 1987;36:190191.

7. Crow S: Peracetic acid sterilization: A timely development for a busy healthcare industry. Infect Control Hosp Epidemiol. 1992; 13:2.

8. Marshburn PB, Rutala WA, Wannamaker NS, et al. Microbiological studies of gas and steam sterilization of assembled versus disassembled laparoscopic equipment. JReprod Med. 1991; Jul; 36(7):483487.
9. Corson SL, Block S, Mintz C, et al. Sterilization of laparoscopes: Is soaking sufficient? JReprod Med. 1979; 23:4956.

10. Ad Hoc Committee on Infection Control in the Handling of Endoscopic Equipment (Association for Practitioners in Infection Control). Guidelines for preparation of laparoscopic instrumentation. AORNJ. 1980;32:6576. .

11. Ayliffe GAJ: Equipment-related infection risks. $J$ Hosp Infect. 1988; II(suppl. A) 279284.

12. Axon ATR, Bond W, Bottrill PM, et al. Endoscopic disinfection. In Working Party Reports, World Congress of Gastroenterology, Sydney, Australia. Blackwell Scientific Publications, 1990. p. 4550.

13. Bond WW, Ott B J, Franke KA, et al. Effective use of liquid chemical germicides on medical devices: Instrument design problems. In: Block SS, ed. Disinfection, Sterilization, and Preservation 4th ed. Philadelphia: Lea \& Febiger, 1991. p 1097.

14. Ridgway GL: Decontamination of fiberoptic endoscopes. I Hosp Infect. 1985; 6:363368.

15. Corson SL, Dole M, Kraus R, et al. Studies in sterilization of the laparoscope II. J Reprod Med. 1979;23:5759. 